\title{
INVESTIGATION OF SOCIO-ECONOMIC AND ENVIRONMENTAL FUNCTIONS OF URBAN GREEN SPACE
}

\author{
Farid Pirmoradian $^{1 *}$ Iraj Ashtari $^{1}$ \\ ${ }^{1 *}$ Iran University of Science and Technology, Master of Civil Engineering (Construction engineering and \\ Management), Tehran Iran;
}

"Corresponding author Farid Pirmoradian, e-mail: pirmoradian@aftermail.ir;

Received December 2019; Accepted January 2020; Published February 2020;

DOI: https://doi.org/10.31407/ijees10.124

\begin{abstract}
With the expansion of urbanization and environmental problems and the resulting social damages, efforts to restore nature to the daily lives of city dwellers have become one of the main concerns of planners and officials. Therefore, the present study aimed to investigation of socio-economic and environmental functions of urban green space. The research method in this study is descriptive-analytical and the information is obtained through library studies and indirect observations, i.e. reading books and related articles. Public green spaces, especially urban parks, in the contemporary urbanized world should be seen as the beating heart of cities they are not only modulating the air in cities and reducing various noise, visual, olfactory, etc. pollution in urban spaces, rather, their indirect social, cultural, and economic functions play a central role in promoting the quality of life of citizens. Considering the important functions of urban green space and their important role in sustainable urban development, we find that creating a favorable green space is the solution to many acute urban problems. In addition to enhancing the quality of the city's landscape, it is effective in aesthetics and identity perception, which can prevent economic and physical damage to the quality of life, pollution, congestion and displacement of the middle class and brought vitality to the central areas of the city and its surroundings and it encourages people to volunteer, and on the other hand, given the components and pillars of sustainable development and their connection to the green space, we can move closer and closer to the goals of sustainable urban development by expanding and paying more attention to urban green spaces.
\end{abstract}

Keywords: socio-economic functions, environmental functions, urban green space 